\title{
CLEONICE ASSUMPCÃO ALAKIJA: \\ A TRAJETÓRIA DE UMA DAS PRIMEIRAS MÉDICAS NEGRAS DE SALVADOR (1910-2000)
}

SIVALDO REIS SANTOS*

UNIVERSIDADE FEDERAL DA BAHIA SALVADOR - BAHIA - BRASIL

O presente artigo examina a trajetória de Cleonice Assumpção Alakija, uma das primeiras médicas negras de Salvador. Neste texto, o(a) leitor(a) terá a oportunidade de saber qual foi a importância que família da médica tivera para a sua formação acadêmica, a passagem dela pela Faculdade de Medicina da Bahia e algumas informações sobre a sua vida após a formatura. A questão central da narrativa foi relacionar a

RESUMO trajetória da médica com o contexto histórico em que ela viveu. Para a construção deste texto foram utilizados jornais, revistas e fotografias da Biblioteca Pública do Estado da Bahia e da Hemeroteca Digital Brasileira. Em destaque os jornais: A Tarde, Gazeta de Notícias, Correio da Manhã, O Imparcial e a Revista Bahia Ilustrada.

Palavras- chave: Cleonice Assumpção; Trajetória; Medicina.

In this work, we analyze the appropriation of images and discourses associated with the social representation of science as a marketing strategy in the ads for syphilisdrugs. Our focus of discussion is the advertisements published by the journal Medicina, official journal of the Society of Medicine and Surgery of Paraíba that circulated between the years 1932 and 1942. Emerged as an unfolding of the process of institutionalization of scientific medicine in the state from the 1920 's on,

ABSTRACT Medicina was responsible for building a network of science circulation that connected doctors and readers of Paraíba to national and international production. To discuss these and other issues, we analyzed the advertising of drugs against syphilis in the Editions of the magazine Medicina based on studies by LudwinFleck and Sérgio Carrara on the structuring of syphilis concept and its relationship with the developmente of medical-scientific knowledge.

Keywords: History of Medicine; Advertising; Syphilis. 


\section{CLEONICE E SUA FAMÍLIA}

A historiografia do pós-abolição, no campo da História Social, tem investido bastante em narrativas que revelam a luta e o protagonismo de alguns homens e mulheres negras no Brasil. ${ }^{1}$ São histórias importantes cujas narrativas demonstram o investimento de parte da população negra pela escolarização e o acesso ao ensino superior. A trajetória da primeira médica negra de Salvador, Maria Odília Teixeira (1884-1971), contada pela historiadora Mayara Plascido da Silva é um exemplo relevante e significativo desse processo histórico de luta por cidadania. ${ }^{2}$

Felizmente, a médica e professora Maria Odília Teixeira não foi a única médica negra a ocupar a tradicional e prestigiosa Faculdade de Medicina da Bahia (FAMEB) na Primeira República. Nesse sentido, apresento neste artigo parte da trajetória de Cleonice Assumpção Alakija que compõem o conjunto das primeiras médicas negras de Salvador junto com Maria Odília Teixeira e Itala Silva de Oliveira (SILVA, 2019).

Grande parte das informações que temos sobre a médica Cleonice Assumpção Alakija advém de sua própria família, mais especificamente da sua tia, Ana Alakija, que é jornalista e vive nos Estados Unidos. ${ }^{3}$ Existem também algumas informações sobre ela no jornal A Tarde e em outros periódicos. ${ }^{4}$ Nascida em 1910, na cidade do Salvador, Cleonice teve vida longa, falecendo aos 90 anos de idade, no ano 2000. Seu pai, Maxwell Porfírio de Assumpção Alakija (1871-1933), nasceu em Lagos (Nigéria) e atravessou o Atlântico em fins do século XIX para viver na capital baiana. Advogado e professor de inglês, Maxwell era um profissional liberal prestigiado e respeitado na cidade. A mãe de Cleonice, Ignez Selene Assumpção (1891-1986), por sua vez, era parteira com formação na Faculdade de Medicina da Bahia e exerceu a atividade profissional por vários anos em Salvador. ${ }^{5}$

Cleonice tinha dois irmãos, o mais velho Dalley Maxwell Assumpção (1908-1949) se formou como engenheiro agrônomo em 1931, curiosamente, no mesmo ano de colação de grau

\footnotetext{
${ }^{1}$ A coleção Personalidades negras reúne sete livros que podem ser baixados no site da Universidade Federal Fluminense, link: < Lançamento da coleção "Personagens do Pós-Abolição | Universidade Federal Fluminense (uff.br)>.

${ }^{2}$ SILVA, Mayara Plascido. Maria Odília Teixeira: a primeira médica negra da Faculdade de Medicina da Bahia (1884-1937). Dissertação (Mestrado em História), Universidade Federal da Bahia. Salvador, 2019.

${ }^{3}$ Ana Alakija tem socializado informações sobre a sua família desde a década de 1990, quando trabalhava no editorial do jornal A Tarde. VER: ALAKIJA, Ana. Tradictional Yoruba Nobility in the African Diaspora. The Yoruba in Brazil, Brazilians in Yorubaland: Cultural, Encounter, Resilence, and Hybridity in the Atlantic World. Durham, North Carolina: Carolina Academic Press, 2017.

${ }^{4}$ Gazeta de Notícias (RJ), 13/11/1929, p.1/ Correio da Manhã (RJ), 24/01/1939, p.3. Fontes disponíveis na Hemeroteca Digital da Biblioteca Nacional.

${ }^{5}$ Sobre a trajetória do pai de Cleonice, ver a minha dissertação de mestrado disponível no site do Programa de Pós - Graduação em História da Universidade Federal da Bahia cujo título é: “Como negro que sou”: a trajetória e militância de um africano em Salvador (1871-1933).
} 
da sua irmã. Sobre Dalley há poucas informações, sabe-se apenas que foi viver em Lagos e por lá faleceu. Em relação ao irmão mais novo, George Assumpção Alakija (1921-2005) há mais notícias. Médico-psiquiatra, George desenvolveu uma série de estudos sobre as temáticas da psicossomática e hipnologia em Salvador. Preocupado em manter conexões com seus familiares na Nigéria, George viajou para este país em algumas ocasiões e também ministrou palestras no Centro de Estudos Afro-Orientais (CEAO) sobre a temática racial e a importância das conexões afro- atlânticas. ${ }^{6}$ Segue abaixo uma fotografia da família cuja data e o local do estúdio são desconhecidos.

Figura 1: Família de Cleonice Assumpção

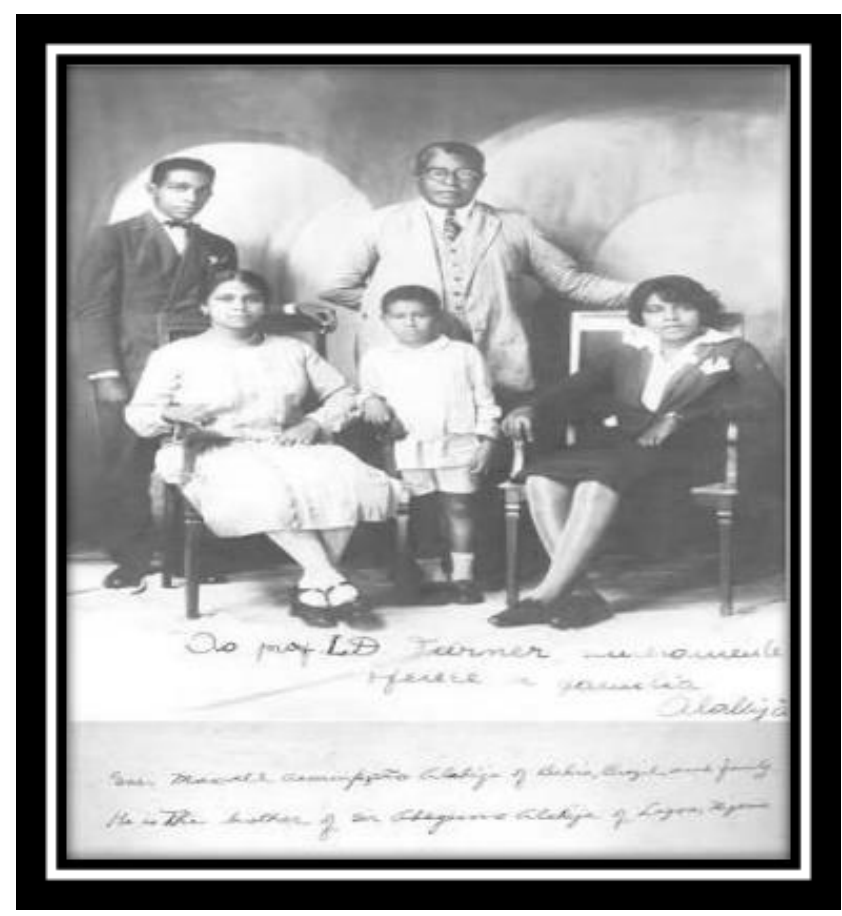

Fonte: Museu afro-digital da memória afro-brasileira Sub coleção Lorenzo Turner

A família vivia na Rua Siqueira Campos, localizada no bairro do Barbalho, região urbana de Salvador. Não podemos assegurar que se tratava de um núcleo familiar com muitas posses, mas seguramente se tratava de uma família que se diferenciava da realidade da maioria das famílias negras de Salvador na Primeira República, sobretudo, no que diz respeito a

\footnotetext{
${ }^{6}$ Jornal A Tarde, 30/10/1976, p.2/ 28/08/1980, p.3/ 28/10/1992, p.4 Biblioteca Pública do Estado da Bahia
} 
escolarização e o acesso ao ensino superior. ${ }^{7} \mathrm{O}$ custeio dos estudos na Faculdade de Medicina da Bahia eram significativos, no caso de Cleonice, seu pai deve ter dado o suporte financeiro necessário. Sua família exercera importância significativa na sua vida, algumas de suas decisões podem ter sido influenciadas por seus pais. A escolha pela medicina, por exemplo, pode ter sido orientada por sua mãe, Ignez Selene Assumpção que, como já destacamos, era uma parteira.

Com a morte prematura e inesperada do pai de Cleonice, em março de 1933, teria a família passado por problemas financeiros? Nesta ocasião, Cleonice Assumpção tinha 23 anos de idade, seu irmão mais velho 25 , e o mais novo apenas 12 anos. O que podemos assegurar é que a família se manteve unida. Ao longo dos anos pesquisadores estrangeiros entraram em contato com eles no intuito de saber informações sobre o passado do patriarca da família e suas ligações com a África. O sociólogo norte- americano Donald Pierson (1935-1937), o estudioso de línguas, também americano, Lorenzo Dow Turner (1941) e o pesquisador e fotografo francês Pierre Verger (1951) foram alguns dos principais estudiosos a socializar as memórias dos Alakijas. ${ }^{8}$

Não deve ter existido dificuldades na comunicação com estes pesquisadores, graças ao conhecimento da língua inglesa que tinha Cleonice e seus irmãos. Anos depois, a médica e seu irmão mais novo, George Alakija, a exemplo de seu pai, ministraram aulas de inglês particulares em Salvador, talvez para aumentar a renda da família. Agora que sabemos um pouco mais sobre Cleonice e sua família, vamos passar a destacar algumas informações sobre a passagem da médica pela Faculdade de Medicina da Bahia (FAMEB).

\section{A FORMACÃO NA FAMEB E SEU CONTEXTO HISTÓRICO}

Em 1926, com apenas 16 anos de idade, Cleonice Assumpção Alakija começava seus estudos na FAMEB. Enfrentando os preconceitos que insistiam em defender a tese de que a principal função social da mulher era gerar filhos e cuidar do lar, ou mesmo que o sexo feminino

\footnotetext{
${ }^{7}$ BACELAR, Jeferson. A hierarquia das raças: pretos e brancos em Salvador. Rio de Janeiro: Editora Pallas, 2001.

${ }^{8}$ Estes pesquisadores tomaram nota do que ouviram da família Alakija e regimentaram em seus respectivos escritos, VER: PIERSON, Donald. Brancos e pretos na Bahia: estudo de contacto racial. São Paulo: Companhia Editora Nacional, 1971; TURNER, Lorenzo Dow. Some contacts of Brazilian Ex- Slaves With Nigeria, West Africa. The Journal of Negro History, v.27, n.1, 1942, pp.55-67; Revista O Cruzeiro (RJ), 1951, pp. 33, 44, 45, 66. Hemeroteca Digital Brasileira.
} 
não tinha capacidade intelectual necessário para cursar medicina, Cleonice seguiu o caminho de outras médicas que, antes dela, também conseguiram enfrentar o sólido modelo patriarcal de sociedade nas primeiras décadas do século XX. Será que Cleonice se inspirou na trajetória das primeiras médicas negras de Salvador, Maria Odília Teixeira e Itala Silva de Oliveira? Será que pediu ajuda a elas ao longo do seu curso? Apesar de Maria Odília ter migrado para as cidades de Cachoeira e São Felix no Recôncavo baiano logo após a sua formatura em 1909, e de Itala de Oliveira ter também migrado para o Rio de Janeiro depois de sua formatura em 1927, não descartamos a possibilidade de Cleonice ter conhecimento da história destas médicas.

Alguns anos antes de sua formatura em outubro de 1931, Cleonice demonstrava interesse em ajudar os estudantes que não tinham recursos para se manter na Faculdade de Medicina da Bahia. Nesse sentido, em 1930, ela fez parte da Sociedade Beneficência Acadêmica da Faculdade de Medicina. Esta Sociedade foi fundada em 1872 por iniciativa dos estudantes da FAMEB e tinha por finalidade ajudar financeiramente os alunos que não tinham recursos próprios para a matrícula e sustento ao longo do curso. Na Primeira República, essa Sociedade se sustentava com o auxílio dos próprios estudantes e, às vezes, com auxílios financeiros do governo federal. ${ }^{9}$

No quinquagésimo oitavo aniversário da Sociedade Beneficência Acadêmica, Cleonice ocupava o cargo de tesoureira acadêmica. Em 1930, a Sociedade contava apenas com a sua presença feminina, todos os outros cargos eram ocupados por homens. $O$ presidente acadêmico era Edgard Pires Veiga, o vice-presidente José Evangelista de Oliveira, o primeiro secretário Péricles Newton Lemos, segundo secretário Serafim Lopes, orador acadêmico Hélio Simões e Rodrigo Catharino como bibliotecários. A comissão de sindicância era formada por Fernando Leite, Mário Sá e Emílio Diniz. ${ }^{10}$

Não foram localizadas maiores informações sobre a presença de Cleonice nessa Sociedade médica, mas é importante destacar o protagonismo desta jovem mulher negra trabalhando ao lado de outros estudantes, em sua maioria homens brancos. Podemos nos perguntar: como devia ser as conversas? Existia conflitos de gênero e raça? Como era o comportamento dela nesta organização? Não sabemos. O que podemos destacar é que sua função de tesoureira tinha

\footnotetext{
${ }^{9}$ A Tarde, 06/05/1930, p.2 Biblioteca Pública do Estado da Bahia ${ }^{10}$ A Tarde, 06/05/1930, p.2 Biblioteca Pública do Estado da Bahia
} 
relevância já que era a responsável direta pela parte financeira da Sociedade, o que denota também que existia uma relação de confiança por parte dos demais membros da organização sobre a sua atividade.

Além de Cleonice Assumpção, outras cinco médicas se formaram no ano de 1931, a saber: Angélica de Almeida Monteiro, Maria José da Silva, Noélia Augusta da Silva, Olga Lydia da Conceição e Maria José Salgado Lages. Todas elas eram mulheres brancas. Das seis mulheres formadas, quatro se tornaram professoras da FAMEB: Angélica Monteiro, na cadeira de Clínica Pediátrica Médica e Higiene Infantil. Noélia Agusta da Silva, Maria José Salgado Lages e Cleonice Assumpção na mesma cadeira de Otorrinolaringologia. ${ }^{11}$

A especialidade médica de Cleonice foi na área de otorrinolaringologista, que é o profissional habilitado para tratar das doenças do nariz, ouvido e garganta. Segundo informações da sua tia, Ana Alakija, Cleonice teria sido a primeira médica negra de Salvador a colar grau e depois trabalhar nesta especialidade médica, mas ainda não foi localizado fonte documental que comprove esta informação. A passagem da médica na FAMEB foi destacada no jornal A Tarde por um longo texto, escrito por autor (a) anônimo em 1931. A narrativa exaltava as qualidades pessoais de Cleonice, sua capacidade intelectual, o bom relacionamento com os colegas e os desafios que a médica enfrentou ao longo do curso. ${ }^{12}$

Pelo tom pessoal, afetivo e descritivo do texto é provável que o autor (a) tenha sido seu colega de curso. Em um trecho da narrativa foi destacado o seguinte: “[...] atravessou a soalheira ingrata do curso médico, ao ritmo embalador de sua tenacidade". Ao lado do texto, aparece a foto de Cleonice com a beca tradicional de formatura que pode ser visualizada na página seguinte. ${ }^{13}$

\footnotetext{
11 AZEVÊDO, Eliane Elisa de Souza; FORTUNA, Cristina Maria Mascarenhas. Exercício de docência por mulheres na FMB- Curso de Medicina (1893-1938). Salvador, Faculdade de Medicina da Bahia, 2012.

12 Jornal A Tarde, 13/10/1931, p.2 Biblioteca Pública do Estado da Bahia.

13 Jornal A Tarde, 13/10/1931, p.2 Biblioteca Pública do Estado da Bahia.
} 
Figura 2 - Cleonice Assumpção Alakija

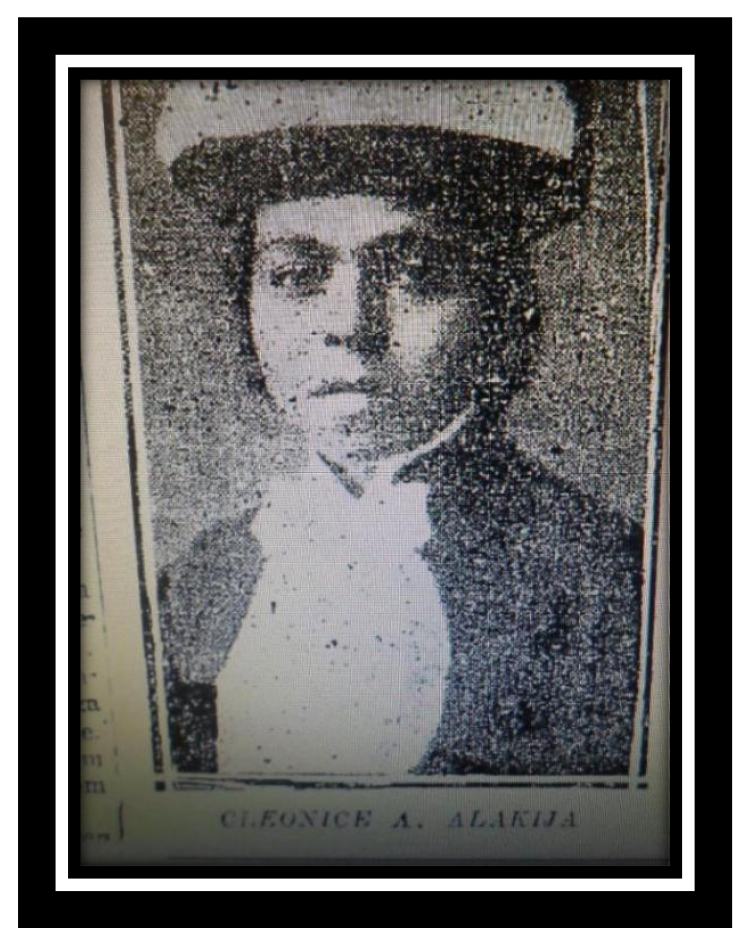

Fonte: Jornal A Tarde, 13/10/1931, p. 2.

A soalheira ingrata do curso médico" foi a forma que o autor encontrou para destacar o quanto era difícil para uma mulher negra adentrar, se sustentar e colar grau em um curso ainda fortemente tradicionalista cuja presença masculina e branca permanecia majoritária na década de 1930. No intuito de animar a recém-formada para os desafios da profissão, o autor (a) teceu as seguintes considerações: "“[...] não tenhas medo da pateada da plateia humana. Não é muito escondido, não te assustará o berreiro do contra- regra da desilusão... vencerás". ${ }^{14}$

Em algumas passagens do texto, o autor destaca a atitude de Cleonice frente as adversidades que seus colegas enfrentavam ao longo do semestre:

[...] e nos momentos de melancolia, quando o sexto e último círculo desse glorioso inferno distanciava-se, ainda pesavam sobre os ombros a vanguarda ameaçadora das injustiças e a hora final do ano letivo avizinhava-se torturante, era ela, sempre ela que vinha consoladora, com uma carícia, simples como uma lágrima; - vocês passam... ora que tolice. ${ }^{15}$

\footnotetext{
${ }^{14}$ Ibidem; 1931, p.2

${ }^{15}$ Jornal A Tarde, 13/10/1931, p.2 Biblioteca Pública do Estado da Bahia.
} 
Não seria equivocado imaginar que Cleonice Assumpção era uma mulher de personalidade forte, que buscava enfrentar os desafios do curso médico com bastante altivez. Outra característica de sua pessoa presente no texto era o seu gosto por viagens: Recife, Rio de Janeiro e até mesmo a Alemanha, foram alguns dos lugares que ela visitou e provavelmente aprendeu com alguns conceitos e técnicas modernas de sua profissão.

Apesar dos desafios e dificuldades a que estava submetida uma mulher negra no universo de uma instituição tradicional, majoritariamente masculina e bastante prestigiada como a FAMEB, sua experiência no ensino superior pode ter sido amenizada com a presença de mais mulheres no curso que, a exemplo da própria Cleonice, também demonstravam muito profissionalismo e determinação como relata a médica Maria José Salgado Lages (1907-2003) em carta enviada à sua mãe no ano de 1928: "continuo satisfeita com a escolha que fiz, o entusiasmo pela clínica começa a aumentar em razão direta dos dias que passam. O tempo dedicado ao estudo é o mais bem empregado". ${ }^{16}$

Cleonice Assumpção, Maria José Salgado Lages e as outras médicas formadas em 1931, fizeram parte de uma crescente geração de mulheres que passaram a acessar o ensino superior e a concluir seus cursos. Esta realidade foi notada por parte da imprensa de Salvador. A revista Bahia Ilustrada que costumeiramente trazia em suas páginas fotos de homens pertencentes a classe social mais alta de Salvador, passou a destacar com maior regularidade fotografias de mulheres formadas. Em sua esmagadora maioria, mulheres brancas. Na figura 3, apresentada na página seguinte, destacamos uma página da revista Bahia Ilustrada em novembro de 1933, que traz a foto de 8 mulheres formadas nos cursos de magistério, música e medicina. Seus nomes: Odette Crusoe e Julia Crusoe (Professoras) e, provavelmente irmãs, por terem o mesmo sobrenome e serem parecidas fisicamente. Alina B. Almeida Sousa (Doutora pela FAMEB), Selene Souza (Professora), Florinda Costa (Musicista), Eulalia Pires Navarro de Andrade (Professora da Escola Normal), Beatriz Aguiar Benevides (Professora da Escola de Música), Argentina Menendez (Musicista). ${ }^{17}$

Chama atenção na fotografia que a maioria das mulheres estavam vestidas de terno e gravata borboleta como as possíveis irmãs, Odette Crusoe e Julia Crusoe (posicionadas acima, na direita

\footnotetext{
16 CHALITA, Solange Lages; MEIRELLES, Roberto Campos. Lily Lages. Artigo disponível em> http://www.aborlccf.org.br/imageBank/Lily_Lages.pdf.

${ }^{17}$ Revista Bahia Ilustrada, 1933, p.27. Hemeroteca Digital Brasileira
} 
e esquerda). Não sabemos se foi uma imposição da revista, se houve conselho de familiares, sobretudo, dos pais e maridos, ou se elas escolheram por conta própria serem fotografadas vestidas dessa forma. É possível que houvesse um pouco de cada coisa. Apesar da crescente participação feminina em alguns cursos superiores na década de 1930 e toda militância feminista impulsionada por Bertha Maria Julia Lutz (1894-1976), a força do patriarcado ainda se fazia presente, condicionando às decisões de muitas mulheres. Bertha Lutz foi uma defensora incansável dos direitos das mulheres no Brasil, inclusive do direito ao voto, à educação e a formação científica. Em 1919, ela prestou concurso para o Museu Nacional, onde trabalhou por quarenta e seis anos e construiu uma reputação internacional como cientista. Fundou a associação feminista intitulada Liga Pela Emancipação Intelectual da Mulher, dedicando-se às ciências e ao movimento feminista. ${ }^{18}$

Figura 3 - Diplomadas

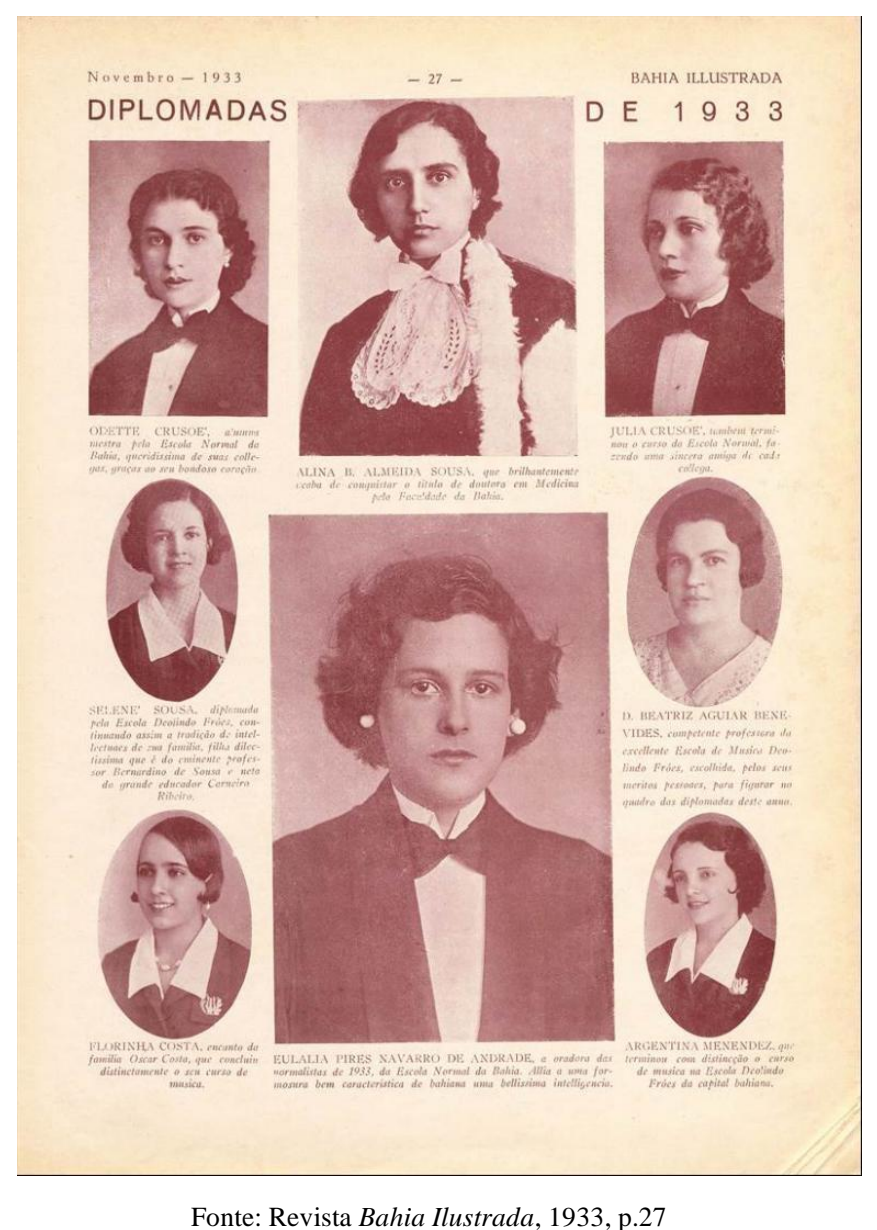
18 SOUZA, Maria Izabel Siciliano; MENDES, Maria Ferreira Abdala. A formação científica e profissional das mulheres no Brasil: a
contribuição de Bertha Lutz. Revista História da Ciência e Ensino, vol. 18, 2018, p.22 
Para que o leitor perceba com mais nitidez a força da sociedade patriarcal na capital baiana nas primeiras décadas do século XX, destacamos uma matéria do jornal Imparcial publicada no dia 6 de agosto de 1935. A matéria apresentava em sua primeira página uma fotografia das primeiras mulheres diplomadas na Academia Brasileira de Corte e Alta Costura fundada no dia 1 de janeiro de 1935 "por força do decreto n.1090". O título da matéria do Imparcial foi: $O$ feminismo bem orientado. O autor da matéria, provavelmente um jornalista do sexo masculino, elogiava a organização e competência da Academia que era presidida por um homem, o professor Francisco Hermaro de Santana" ${ }^{19}$

Por que "feminismo bem orientado"? O que seria um "feminismo mal orientado"? Seguramente, o "movimento feminista mal orientado" era aquele que questionava os padrões rígidos do patriarcado, que desafiava os privilégios dos homens no dia a dia e que lutava pela igualdade de direitos entre homens e mulheres. ${ }^{20}$ Podemos considerar que O Imparcial elogiava a diplomação das mulheres na Academia Brasileira de Corte e Costura, porque esta atividade profissional remetia ao trabalho no lar, no ambiente doméstico. Ainda nos anos de 1930, quando a médica Cleonice Assumpção começava a sua atividade profissional, permanecia cristalizado a defesa nos valores patriarcais que supervalorizava o trabalho feminino no ambiente doméstico.

Sobre as mulheres diplomadas, foram doze no total, seus nomes: Maria de Lourdes, Dorea Cunha, Arabella Nonato Marques, Suzana Valverde, Alda Machado, Judith Pinto, Regina Sandes, Izaura Cravo Caldeira, Nair Carvalho, Julieta Maria dos Santos, Therezinha Gonçalves do Couto e Antonieta Alves. Depois da cerimônia de diplomação, elas se dirigiram para a igreja no Convento da Lapa para realização de uma missa em ação de graças que foi "assistida por numerosas famílias". Em seguida, dirigiram-se todas para o Ginásio da Bahia (instituição pública que ministrava o ensino secundário em Salvador). Nesta instituição foram entregues os diplomas.

\footnotetext{
${ }^{19}$ O Imparcial, 06/08/1935, p.1 Hemeroteca Digital Brasileira.

${ }^{20}$ MONFARDINI, Júlia. Uma história do feminismo no Brasil. Caderno Espaço Feminino. V.30, n.1, 2017.
} 
Figura 4 - As primeiras diplomadas

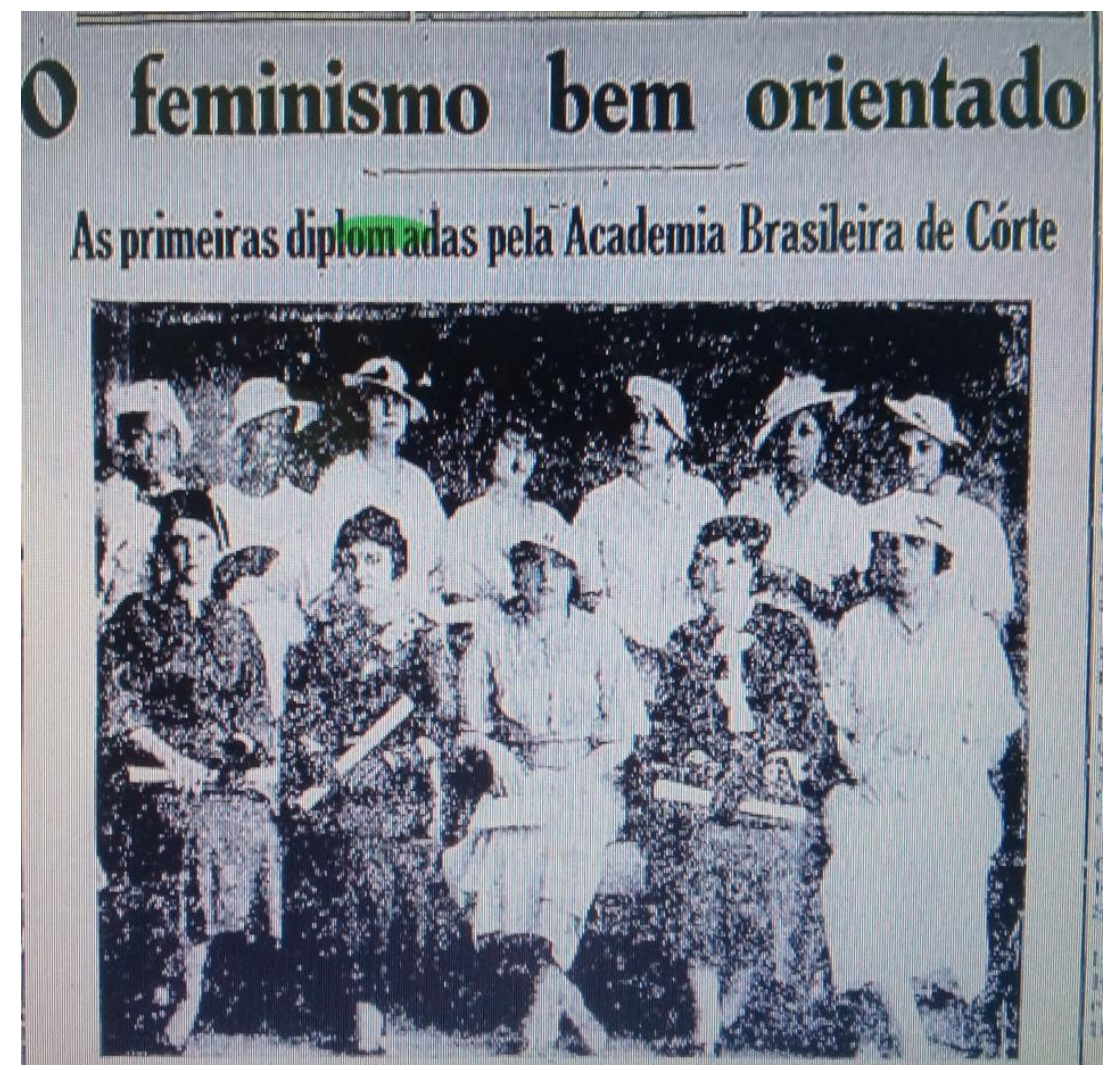

Fonte: O Imparcial, 08/08/1935, p.1.

Na fotografia, vê-se que há quatro mulheres negras, duas em pé do lado direito e duas do lado esquerdo. Qual era a importância para estas mulheres receberem o diploma de corte e alta costura? Do ponto de vista financeiro, poderia significar a oportunidade de trabalhar em fábricas de roupas, atelier de costura etc. A luta pelo diploma, uma especialização, podia estar diretamente relacionada ao trabalho e, consequentemente, independência financeira dos seus maridos e pais. Nesse sentido, as ideias do jornalista que escreveu a matéria sobre o feminismo bem orientado podiam não estar em consonância com o que pensavam estas mulheres que estavam lutando por uma melhor qualificação no mercado de trabalho e por suas vidas, bem como a médica Cleonice Assumpção Alakija. 


\section{A VIDA DEPOIS DE FORMADA}

Eis médica. Na otorrinolaringotogia de sólida e culta. O segredo das sinusites tem para tua ciência o prestígio infantil de um brinquedo... com a luz de tua lâmpada frontal levas a cura e o bem estar... que mais queres? tens um magnifico lugar na ribalta. $^{21}$

Depois de formada, Cleonice seguiu um roteiro diferente das duas primeiras médicas negras formadas na Faculdade de Medicina da Bahia que, por motivos diversos, não permaneceram em Salvador. Cleonice ficou na capital baiana e, um ano após a formatura, assumiu a cadeira de Otorrino na FAMEB. Em 1934 ela começou a trabalhar em seu consultório particular que ficava localizado na rua Chile, em Salvador, prédio Catarino, primeiro andar. As consultas eram das 14:00 às 16:00 horas. ${ }^{22}$

Não foi possível localizar nas fontes maiores detalhes sobre a atividade docente de Cleonice Alakija na FAMEB, nem em seu primeiro consultório particular. Mas, sabemos que Cleonice mudou de consultório, da Rua Chile para o Relógio de São Pedro, região comercial e bastante movimentada de Salvador. ${ }^{23}$ Trabalhar em um consultório particular representava a oportunidade de ter uma renda a mais e, também, ajudar os necessitados. Foi assim que, logo depois de formada, a colega de turma de Cleonice, Maria José Salgado Lages, instalou sua clínica de Otorrino no primeiro andar de um prédio na Rua do Comércio, no centro de Maceió (Alagoas). Segundo Solange Lages Chalita e Roberto Campos Meires, a médica atendia gratuitamente às segundas e quartas feiras. ${ }^{24}$

Além das aulas e do trabalho na clínica particular, Cleonice fez parte da primeira Diretoria da Sociedade de Oftalmologia e Otorrinolaringologia da Bahia, fundada em 16 de junho de 1937. Curiosamente, ela assumiu o mesmo cargo de tesoureira quando atuava na Sociedade de Beneficência Acadêmica. em 1930. E mais uma vez, ela era a única mulher a compor o quadro de uma Sociedade médica. A Sociedade de Oftalmologia e Otorrinolaringologia de 1937, contava como presidente o Dr. Hildebrando Jatoba, vice-presidente, o Dr. Carlos Moraes, primeiro secretário, o Dr. Adroaldo de Alencar, e o segundo secretário, Dr. Bahia Monteiro.

\footnotetext{
${ }^{21}$ Jornal A Tarde, 13/10/1931, p.2 Biblioteca Pública do Estado da Bahia.

22 Jornal A Tarde, 25/10/1934, p.7 Biblioteca Pública do Estado da Bahia.

${ }^{23}$ Jornal A Tarde, 12/03/2000, p.8 Biblioteca Pública do Estado da Bahia

${ }^{24}$ CHALITA; MEIRELES, 2003, p. 2.
} 
Esta sociedade tinha por finalidade principal contribuir para o estudo das questões que se relacionavam com a oftalmologia e a otorrinolaringologia, e para o aperfeiçoamento destas especialidades medicas.É importante destacar que os membros- diretores desta Sociedade foram eleitos em uma assembleia geral pela comunidade dos médicos especialistas da área, o que denota respeito pelo trabalho realizado pela Cleonice por parte dos seus colegas. ${ }^{25}$

Dedicada à medicina, Cleonice teve a oportunidade de ser homenageada em público em algumas ocasiões. Em fevereiro de 1993, os antigos alunos da Faculdade de Medicina da Bahia, juntamente com a sua Diretoria, homenagearam os médicos com mais de 50 anos de profissão presenteando-os com diplomas de honra ao mérito em uma sessão solene. O evento aconteceu no salão nobre da Faculdade, no Terreiro de Jesus. Foram 59 médicos homenageados, 54 homens e apenas 5 mulheres. Além de Cleonice, estavam presentes no evento as médicas: Lídia Paraguassu, Nair Guena, Lucy Hiltner e Nair Tourinho. ${ }^{26}$ A fonte é uma evidência documental muito convincente da superioridade masculina no curso de medicina ao longo do século XX na Bahia.

Em 1993, quando foi homenageada pela Faculdade de Medicina da Bahia, Cleonice já era uma mulher idosa, com 83 anos de vida. Quando chegou aos 90 anos, no ano 2000, ela continuava trabalhando em sua clínica particular localizada no Relógio de São Pedro. O jornal A Tarde destacou que, por mais de 30 anos, ela trabalhou nos Centros de saúde do estado da Bahia e no Instituto Nacional de Assistência Médica da Previdência Social- INAMPS, criado em 1977, e extinto em 1993, pela lei n.8.689. ${ }^{27}$

Foi realizada uma pesquisa nos arquivos do INAMPS, mas o nome da médica Cleonice Assumpção não foi localizado. ${ }^{28}$ É possível perceber que a trajetória profissional desta médica logo após a formatura foi de muito trabalho. Suas atividades não se limitaram as aulas na FAMEB, nem atendimento aos seus clientes. Como já observamos, ela integrou uma Sociedade médica com a finalidade de estudar e se aprofundar nos conhecimentos relacionados a sua especialidade, otorrinolaringologia.

\footnotetext{
25 Revista BJORL- Brazilian Journal of Otorhinolaryngology. Ano: 1937, vol.5, p.457-498. Acessar em> http://oldfiles.bjorl.org/conteudo/acervo/acervo.asp?id=593.

${ }^{26}$ A Tarde, 15/02/1993, p.2 Biblioteca Pública do Estado da Bahia

${ }^{27}$ A Tarde, 12/03/2000, p.8 Biblioteca Pública do Estado da Bahia.

28 A fonte acessada, esta disponível em> http://www.fgv.br/cpdoc/acervo/dicionarios/verbete-tematico/instituto-nacional-de-assistenciamedica-da-previdencia-social-inamps.
} 


\section{CONSIDERACÕES FINAIS}

Cleonice Assumpção Alakija faleceu aos 90 anos de idade, no Hospital Português, no ano 2000. ${ }^{29}$ No ano do seu falecimento, ela residia na Avenida Euclides da Cunha, bairro da Graça, em Salvador. Ela morreu solteira e sem deixar filhos. ${ }^{30}$

É evidente que toda a trajetória de sucesso que Cleonice construiu na medicina não foi apenas resultado do seu esforço pessoal. Sua família tivera importância significativa neste processo. Seu pai, Maxwell Assumpção, era um profissional liberal que dedicava uma atenção especial ao conhecimento e a ciência, nesse sentido, não deve ter resistido ao desejo da filha pela medicina, diferente de muitos pais e maridos que ainda na década de 1930, resistiam ao ingresso de suas filhas em cursos que eram tradicionalmente ocupados por homens. Em relação a sua mãe, Ignez Selene, esta sim pode ter sido sua principal referência, parteira de longa data na cidade e com passagem pela Faculdade de Medicina, Ignez Selene seguramente desenvolveu muitas conversas com a sua filha, orientando e estimulando seu ingresso na FAMEB.

Podemos especular que a própria Cleonice possa ter exercido alguma influência na decisão pela medicina do seu irmão mais novo, George Alakija, que desenvolveu um importante trabalho médico em Salvador no campo da psiquiatria sendo reconhecido e premiado algumas vezes, sua trajetória ainda está por ser escrita também.

Cleonice Assumpção Alakija é, sem sombra de dúvida, uma das personalidades negras mais importantes para o estado da Bahia e, porque não dizer, do Brasil? Com apenas 21 anos de idade conseguiu seu título de doutora num contexto em que pouquíssimas mulheres negras conseguiam tal feito. As fontes localizadas para a construção deste artigo nos permitiram traçar um pouco de sua personalidade e conseguimos enxergar uma mulher determinada, que soube enfrentar os desafios de seu tempo histórico com bastante altivez.

As trajetórias das pioneiras médicas negras de Salvador; Maria Odília Teixeira, Itala Silva de Oliveira e Cleonice Assumpção Alakija, nos remete para a importância de mais pesquisas que possam dar visibilidade a outras mulheres que conseguiram transpor as barreiras do racismo e do patriarcado, e que conseguiram acessar diferentes lugares sociais de prestígio na sociedade baiana. Seguramente, a Faculdade de Medicina da Bahia também ganhou com a passagem

\footnotetext{
${ }^{29}$ A Tarde, 08/08/2000, p.6 Biblioteca Pública do Estado da Bahia. ${ }^{30}$ A Tarde, 08/08/2000, p.6 Biblioteca Pública do Estado da Bahia.
} 
destas três médicas e de outras profissionais que, alinhando conhecimento com responsabilidade social, fizeram a diferença em contextos históricos desafiadores.

\section{REFERÊNCIAS}

Fontes

BIBLIOTECA PÚBLICA DO ESTADO DA BAHIA. Jornal A Tarde, anos indicados.

HEMEROTECA DIGITAL BRASILEIRA DA BIBLIOTECA NACIONAL. Revista Bahia Ilustrada, anos indicados.

HEMEROTECA DIGITAL BRASILEIRA DA BIBLIOTECA NACIONAL. O Imparcial, anos indicados.

HEMEROTECA DIGITAL BRASILEIRA DA BIBLIOTECA NACIONAL. Gazeta de Notícias (RJ), anos indicados.

HEMEROTECA DIGITAL BRASILEIRA DA BIBLIOTECA NACIONAL. Correio da Manhã (RJ), anos indicados.

Revista BJORL- Brazilian Journal of Otorhinolaryngology. Ano: 1937, vol.5, p.457-498. Disponível em < http://oldfiles.bjorl.org/conteudo/acervo/acervo.asp?id=593>. Acesso: mai. 2021.

\section{Obras Gerais}

ALBUQUERQUE, Wlamyra Ribeiro de. O jogo da dissimulação: abolição e cidadania negra no Brasil. São Paulo: Companhia das Letras, 2009.

ALAKIJA, Ana. Tradictional Yoruba Nobility in the African Diaspora. The Yoruba in Brazil, Brazilians in Yorubaland: Cultural, Encounter, Resilence, and Hybridity in the Atlantic World. Durham, North Carolina: Carolina Academic Press, 2017.

AZEVÊDO, Eliane Elisa de Souza; FORTUNA, Cristina Maria Mascarenhas. Exercício de docência por mulheres na FMB- Curso de Medicina (1893-1938). Salvador, Faculdade de Medicina da Bahia, 2012.

BACELAR, Jeferson. A hierarquia das raças: pretos e brancos em Salvador. Rio de Janeiro: Editora Pallas, 2001.

MONFARDINI, Júlia. Uma história do feminismo no Brasil. Caderno Espaço Feminino. V.30, n.1, 2017. 
PIERSON, Donald. Brancos e pretos na Bahia: estudo de contacto racial. São Paulo: Companhia Editora Nacional, 1971.

PEREIRA, Almicar Araújo. Paulo Silva: um contraponto nas relações raciais no Brasil. Rio de Janeiro: Editora da Universidade Federal Fluminense, 2020.

SOUSA, Lia Gomes Pinto; SOMBRIO, Mariana Moraes de Oliveira; LOPES, Maria Margareth. Para ler Bertha Lutz. Cadernos Pagu, jan-jun, 2005.

SILVA, Mayara Plascido. Maria Odília Teixeira: a primeira médica negra da Faculdade de Medicina da Bahia (1884-1937). Dissertação (Mestrado em História), Universidade Federal da Bahia, Salvador, 2019.

SANTOS, Ynaê Lopes dos. Juliano Moreira: um médico negro na fundação da psiquiatria brasileira. Rio de Janeiro: Editora Universidade Federal Fluminense, 2020.

SANTOS, Adailton Ferreira. A Faculdade de Medicina da Bahia: percurso e reforma do ensino no século XIX. VIII Seminário Nacional de Estudos e Pesquisas. Campinas, 2009.

SANTOS, Sivaldo dos Reis. "Como negro que sou": a trajetória e militância de um africano na Bahia, Maxwell Assumpção Alakija (1871-1933). Dissertação (Mestrado em História), Universidade Federal da Bahia, Salvador, 2020.

SOUZA, Maria Izabel Siciliano; MENDES, Maria Ferreira Abdala. A formação científica e profissional das mulheres no Brasil: a contribuição de Bertha Lutz. Revista História da Ciência e Ensino, vol. 18, 2018.

TURNER, Lorenzo Dow. Some contacts of Brazilian Ex- Slaves With Nigeria, West Africa. The Journal of Negro History, v.27, n.1, 1942. 